\title{
Insect threats and conservation through the lens of global experts
}

\author{
Milicic, Marija
}

2021-07

Milicic , M , Popov , S , Branco , V V \& Cardoso , P 2021, ' Insect threats and conservation

through the lens of global experts ' , Conservation Letters , vol. 14 , no. 4 , 12814 . https://doi.org/10.1111/conl.1281

http://hdl.handle.net/10138/333563

https://doi.org/10.1111/conl.12814

cc_by

publishedVersion

Downloaded from Helda, University of Helsinki institutional repository.

This is an electronic reprint of the original article.

This reprint may differ from the original in pagination and typographic detail.

Please cite the original version. 


\title{
Insect threats and conservation through the lens of global experts
}

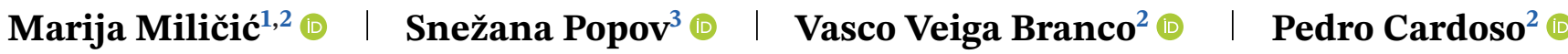

${ }^{1}$ BioSense Institute - Research Institute for Information Technologies in Biosystems, University of Novi Sad, Novi Sad, Serbia

${ }^{2}$ Laboratory for Integrative Biodiversity Research (LIBRe), Finnish Museum of Natural History Luomus, University of Helsinki, Helsinki, Finland

${ }^{3}$ Department of Biology and Ecology, Faculty of Sciences, University of Novi Sad, Novi Sad, Serbia

\section{Correspondence}

Marija Miličić, BioSense Institute-

Research Institute for Information Technologies in Biosystems, University of Novi Sad, Novi Sad, Serbia.

Email:marija.milicic@biosense.rs

Additional supporting information may be found online in the Supporting Information

section at the end of this article.

\section{Funding information}

Koneen Säätiö; Horizon 2020 Framework Programme, Grant/Award Number: 664387; Ministarstvo Prosvete, Nauke i Tehnološkog Razvoja, Grant/Award Numbers: 451-03-9/2021-14/200125, 451-039/2021-14/200358

\begin{abstract}
While several recent studies have focused on global insect population trends, all are limited in either space or taxonomic scope. As global monitoring programs for insects are currently not implemented, inherent biases exist within most data. Expert opinion, which is often widely available, proves to be a valuable tool where hard data are limited. Our aim is to use global expert opinion to provide insights on the root causes of potential insect declines worldwide, as well as on effective conservation strategies that could mitigate insect biodiversity loss. We obtained 753 responses from 413 respondents with a wide variety of spatial and taxonomic expertise. The most relevant threats identified through the survey were agriculture and climate change, followed by pollution, while land management and land protection were recognized as the most significant conservation measures. Nevertheless, there were differences across regions and insect groups, reflecting the variability within the most diverse class of eukaryotic organisms on our planet. Lack of answers for certain biogeographic regions or taxa also reflects the need for research in less investigated settings. Our results provide a novel step toward understanding global threats and conservation measures for insects.
\end{abstract}

\section{KEYWORDS}

agriculture, biodiversity decline, climate change, conservation measures, ecosystem services, expert opinion, extinction, Insecta, land management, pollution

\section{1 | INTRODUCTION}

Insects play a key role in providing numerous irreplaceable services, many of which are critical to human survival and wellbeing. Yet, most insects are noncharismatic at best and perceived as pests at worst. As such, they receive little attention (with a few exceptions, e.g., bees and butterflies, which often capture the public's attention), attracting few resources for monitoring and conservation (Krause \& Robinson, 2017; Mammola et al., 2020). Likewise, recent studies on animal biodiversity confirm an underrepresentation of insects in the published literature (Titley et al., 2017). Nevertheless, declines have not only been observed in relation to insect diversity and abundance (Biesmeijer et al., 2006; Brooks et al., 2012; Roth et al., 2020; Shortall et al., 2009), but also regarding total insect 
biomass. For example, one pioneer study conducted in 63 nature protection areas in Germany showed a dramatic $75 \%$ decline in total flying insect biomass, regardless of habitat type (Hallmann et al., 2017).

When it comes to insect trends and threats, large-scale studies and reviews covering this topic are scarce and plagued by geographic and taxonomic biases (Cardoso et al., 2019; Didham et al., 2020; Montgomery et al., 2020; Simmons et al., 2019), with most literature being highly focused on specific areas (with an overall research bias on the Holarctic) and selected taxa not representative of insects or even of insect subgroups (e.g., the large focus on eusocial bees, only a part of all bees) (Goulson et al., 2015; Wagner, 2020). The highest density of biodiversity research occurs in temperate climates, markedly in Western Europe (Titley et al., 2017). Bearing in mind that an estimated 85\% of insect species are found in the tropics and south temperate regions (Stork, 2018), under-representation of biodiversity and conservation studies in these areas could lead to false notions about the state of insect diversity and their global spatial distribution. Hence, there is an urgent need to know the status of insects across the globe and taxa.

The most comprehensive study to date on insect declines is the one by van Klink et al. (2020). In this paper, the authors analyzed data from a total of 149 studies encompassing 1240 different sites in order to establish abundance trends in populations of terrestrial and freshwater insects. This effort nonetheless suffered from geographic bias with $74 \%$ of studies focusing on the Holarctic region. Additionally, it also lacks an explicit summary of which taxa each of its datasets covered, instead exploring further details on the realms and stratums examined in each set. Finally, the mix of data suffers from several problems of interpretation (Desquilbet et al., 2020). While commendable and a considerable effort on its own, it still leaves much potential variation in the declines of unexplored regions and taxa.

Considering that global monitoring programs are not implemented, and unbiased data are not available (Cardoso \& Leather, 2019), we must look for alternative strategies to advance our knowledge on insects. Here we propose to use expert opinion. It frequently plays a fundamental role in conservation, providing substantive information for decision making processes (Cook et al., 2010), horizon scanning (Sutherland et al., 2004), and risk assessments (Patterson et al., 2007). Moreover, the International Union for the Conservation of Nature (IUCN) species assessments, particularly regarding insects, almost invariably depend on expert scientific judgment, and yet they contribute to measure our progress toward global biodiversity conservation goals. Turning to expert knowledge to generate comprehensive data gives us the opportunity to access and explore valuable nonconventional data, over- coming, at least partially, persisting geographic and taxonomic data biases.

Our research focuses on the latest insights from experts studying a wide variety of insects around the world. We define experts as individuals possessing a high degree of expertise related to insect taxa, including research, decision making, advocacy, applied science, and/or education. Based on expert opinion obtained through the survey tackling questions on main threats, as well as conservation measures for insects, we identify the potential root causes of insect population trends and extinctions across different biogeographical regions and taxa. In addition, we identify effective conservation strategies that could mitigate insect biodiversity loss at a global level.

\section{2 | MATERIAL AND METHODS}

We created a Google form query with 16 questions in six main sections (Supplementary Material). The first set of questions (1-4) aimed to provide information about the demographic structure of the respondents (gender, experience, education, and work responsibilities). Questions 5-7 were intended to reveal their biogeographic and taxonomic expertise, which was used to sub-set the data. In the case of taxonomic groups, we used order level. The only exception was for ants, which were analyzed as a separate group since we considered them to be a distinct entity. Compared to other Hymenoptera, we expected them to suffer from different threats and require different conservation actions. If the respondents' expertise covered several biogeographic regions or taxonomic groups they could select multiple regions and groups if threats and conservation measures were deemed similar. If answers differed, they were encouraged to fill the survey multiple times, one for each region or taxon. Questions 8-9 were related to the services and disservices provided by insects. Questions 10-12 focused on the threats to insect populations and on their current trends. Questions 13-14 addressed the current and potential conservation measures focused toward insects, including allocating potential funds for future projects. Finally, questions 15 and 16 were intended to provide references that support the previous answers and leave any additional comments.

To ensure geographical coverage, we contacted around 100 entomological societies globally (list found on the web page: www.entsoc.org), and asked them to distribute the query among their members. We also contacted approximately 3000 corresponding authors from papers containing the word "insects," published in international journals in the last 10 years, found through Scopus search. Contact emails were extracted manually from each paper. 
To identify the variation in answers in regard to demographic structure of the respondents, biogeographic regions and taxa, we performed PerMANOVA with 99999 permutations within the $\mathrm{R}$ package vegan (Oksanen et al., 2019), using all answers as response variables and demographic structure of the respondents, biogeographic regions and taxa as explanatory variables in the analyses. In cases where respondents answered for multiple biogeographic regions or insect taxa, the answers were analyzed separately within each of the selected regions or orders. To avoid dominance in answers coming from the same respondent, we applied a weighted average, where the weight of each answer was divided by the number of answers coming from the same respondent (for multiple regions or taxa). A weighted average was also used to overcome possible unbalances in the number of answers for different regions or taxa. Answers to questions regarding threats and conservation of insects ranging from 1 to 5 (1, not relevant at all; 2, little relevance; 3 , somewhat relevant; 4 , very relevant; 5 , extremely relevant) were rescaled from 0 to $1(0.2 ; 0.4,0.6,0.8,1)$. The relevance score average was bootstrapped (random selection of elements with repetition) to obtain upper and lower confidence limits. The procedure was conducted for answers from all regions and taxa together for a global analysis, and then separately for all eight biogeographic regions and all taxa for which more than 10 answers were available (the remaining taxa were grouped under "Other").

\section{3 | RESULTS}

We obtained 439 responses. Several doubtful answers were eliminated, which included selection of only "unknown relevance" options in the entire survey, selection of all regions and all orders, or the indication that answers relate to noninsects (spiders). In total, the final data set contained 429 responses from 413 participants. When responses that contained selections of multiple regions or taxa were fragmented, we obtained a total of 753 answers.

\section{1 | Demographic structure of the respondents}

Participants in the survey were predominantly male (298), researchers (359), with more than 10 years of experience (291) and with a PhD (318) (Table S1). The PerMANOVA analysis showed that in most cases, respondent demography did not influence their answers regarding threats and conservation of insects (Table S2). However, there was within-group variation in answers based on respondents' education. To account for this, all consecutive analyses were conducted in two ways: (1) analyzing all answers together, and (2) analyzing answers from respondents holding a $\mathrm{PhD}$ degree versus answers from all respondents with other levels of education. Separate analyses are presented in Supplementary Material (Figures S1-S8). In general, the results between two groups were broadly similar, with main difference being that respondents with other levels of education placed smaller weight to agriculture as a threat, than $\mathrm{PhD}$ holders.

\section{2 | Answers per region and taxon}

Expertise on the Western Palearctic (Figure 1) and on the orders Coleoptera, Lepidoptera, and Diptera were dominant (Figure 2). The PerMANOVA analysis showed that there were statistically significant differences in answers, based on both biogeographic region and taxon (Table S4).

\section{3 | Threats}

At a global level, the most relevant threats for insects identified by the survey were agriculture and climate change, followed by pollution, natural system modifications, invasive species, and residential and commercial development, which all were significantly different from the first two, as shown by the bootstrap analysis (Figure 3). The Afrotropical, Neotropical, Western Palearctic, and Nearctic followed the global pattern regarding the three top-rated threats. In the Eastern Palearctic, Indomalayan, Australasian, and Oceanian regions, residential and commercial development was among the top-rated threats. The most noticeable difference was in Oceania, where coextinctions were listed among the most significant threats, next to those coinciding with the global pattern (Figure 3).

In most cases, analyses per insect order revealed that the trends followed the global pattern, with agriculture, climate change, and pollution being identified as the most important threats for most orders (Figure 4). Contrastingly, for the aquatic taxa (Ephemeroptera, Plecoptera, and Trichoptera-EPT), however, natural system modifications were selected as the most relevant threat. These were also among the most significant responses for Odonata. For ants, in addition to agriculture and natural system modifications, invasive species were among the top-rated threats, with no statistical differences from the first two.

\section{4 | Population trends}

There was a perceived decreasing trend in almost all biodiversity parameters, excluding phylogenetic and functional 


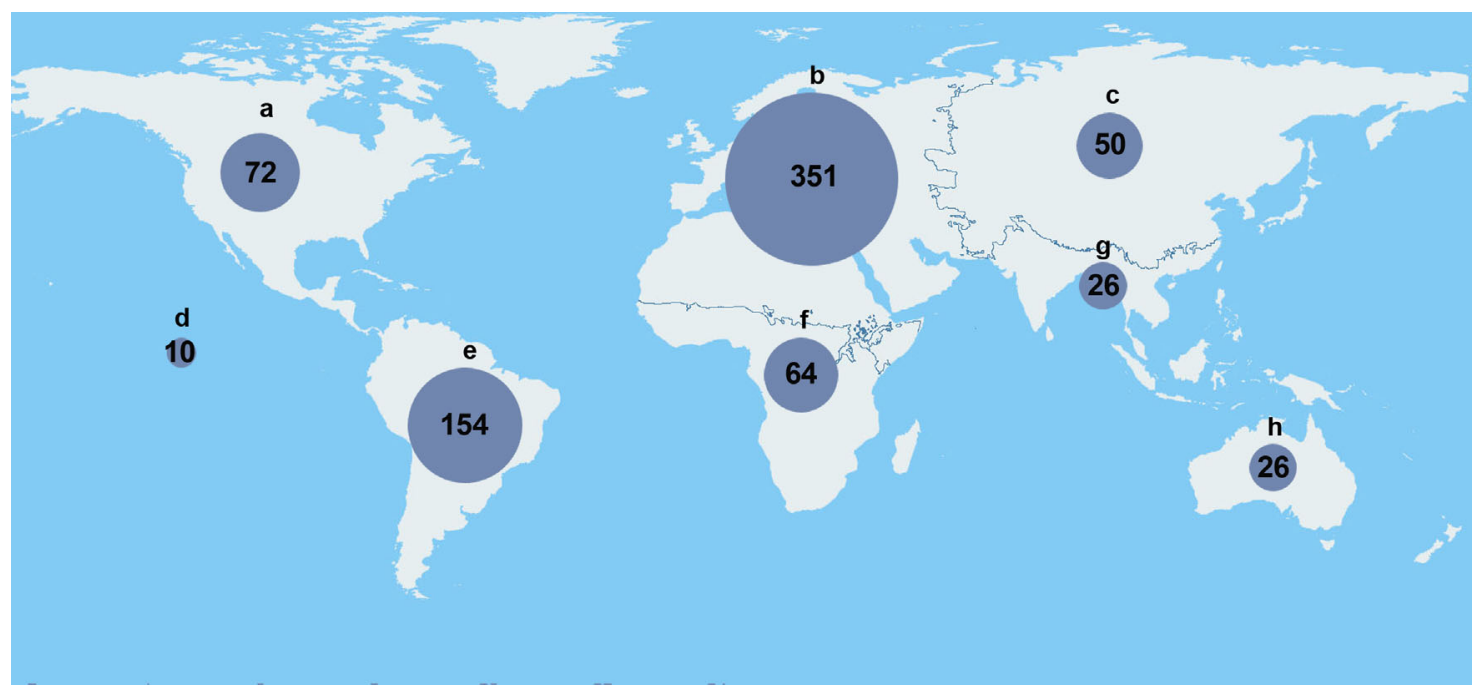

F I G U R E 1 Distribution of answers (with number of respondents) per biogeographical region. Biogeographic regions: a, Nearctic; b, Western Palaearctic; c, Eastern Palaearctic; d, Oceania; e, Neotropics; f, Afrotropics; g, Indo-Malaya; e, Australasia

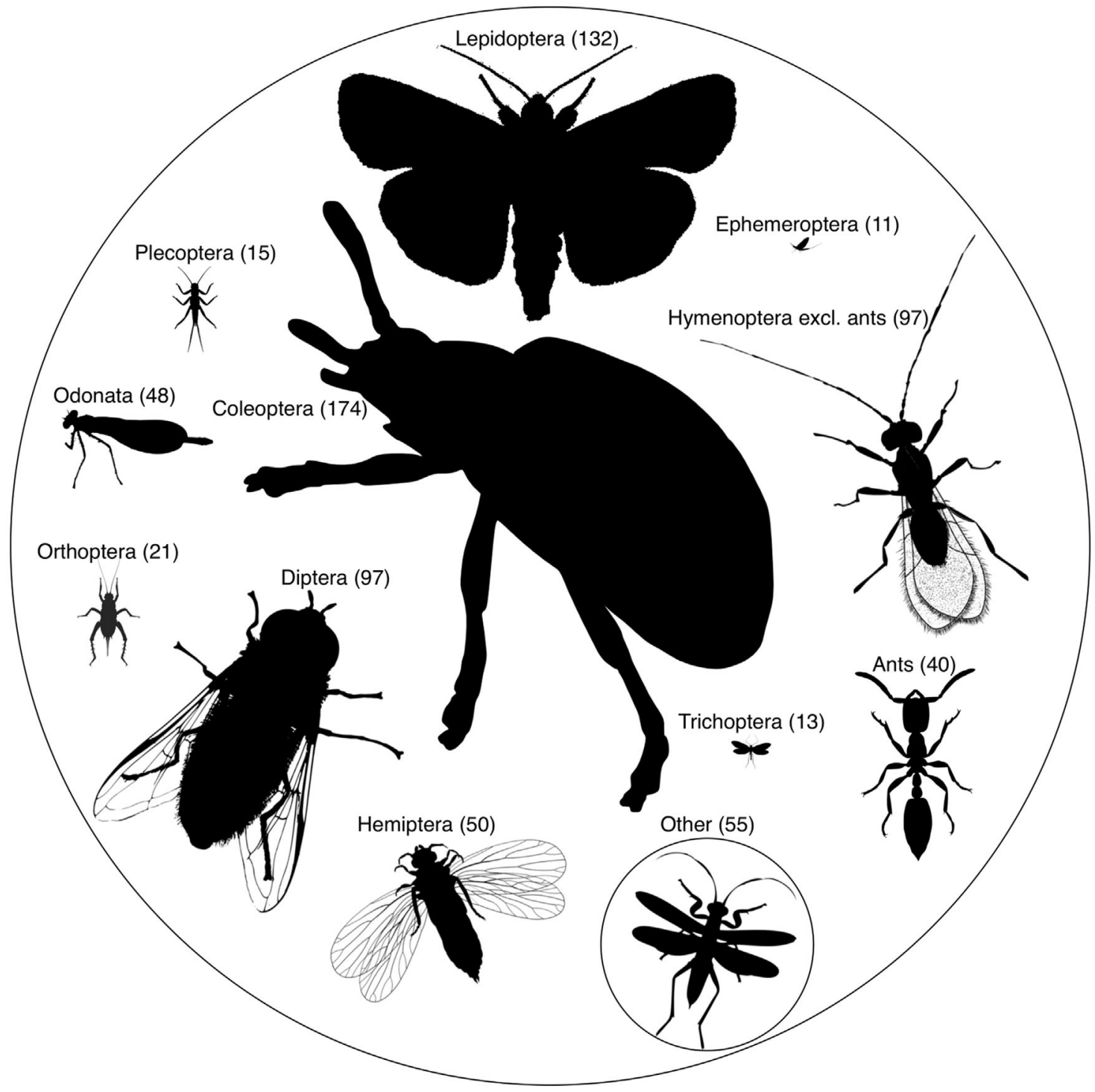

F I G U RE 2 Distribution of answers (with number of respondents) per insect order 


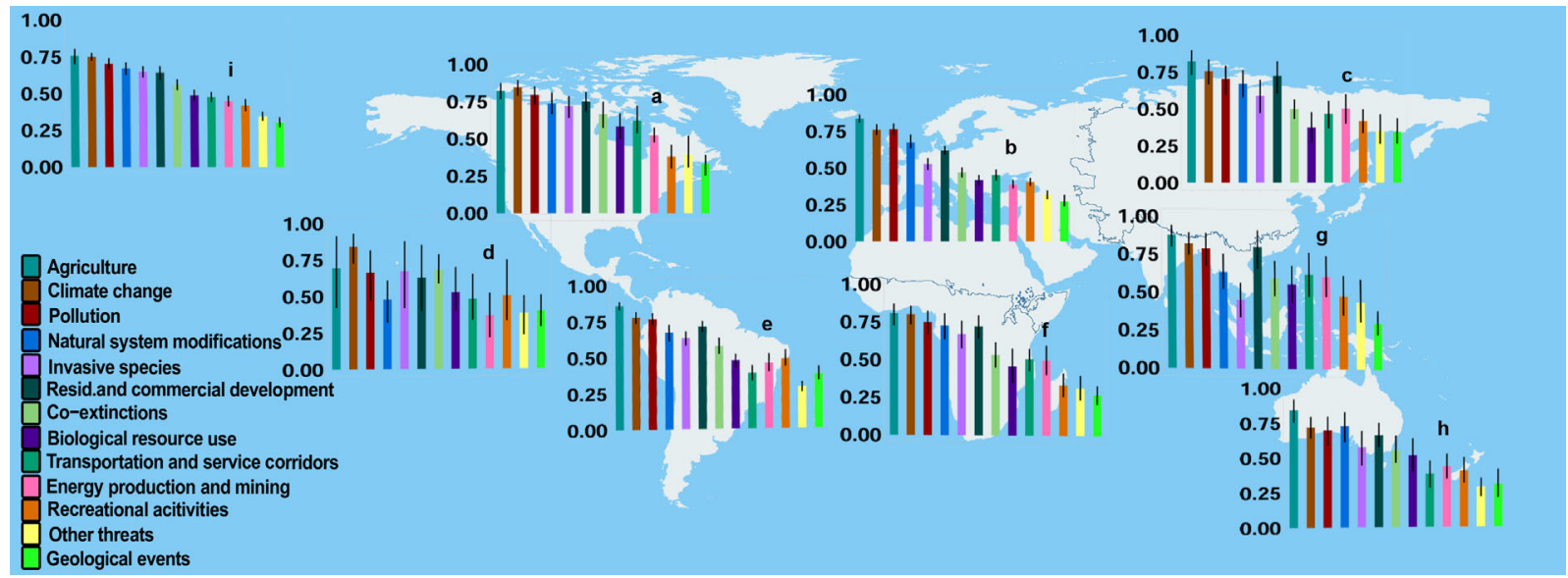

F I G U R E 3 Global and biogeographic section-based significance of most relevant threats for insects. Confidence limits were calculated by bootstrap. Bars represent average relevance scores for each threat based on answers from respondents. Biogeographic regions: a, Nearctic; b, Western Palaearctic; c, Eastern Palaearctic; d, Oceania; e, Neotropics; f, Afrotropics; g, Indo-Malaya; e, Australasia; i, global
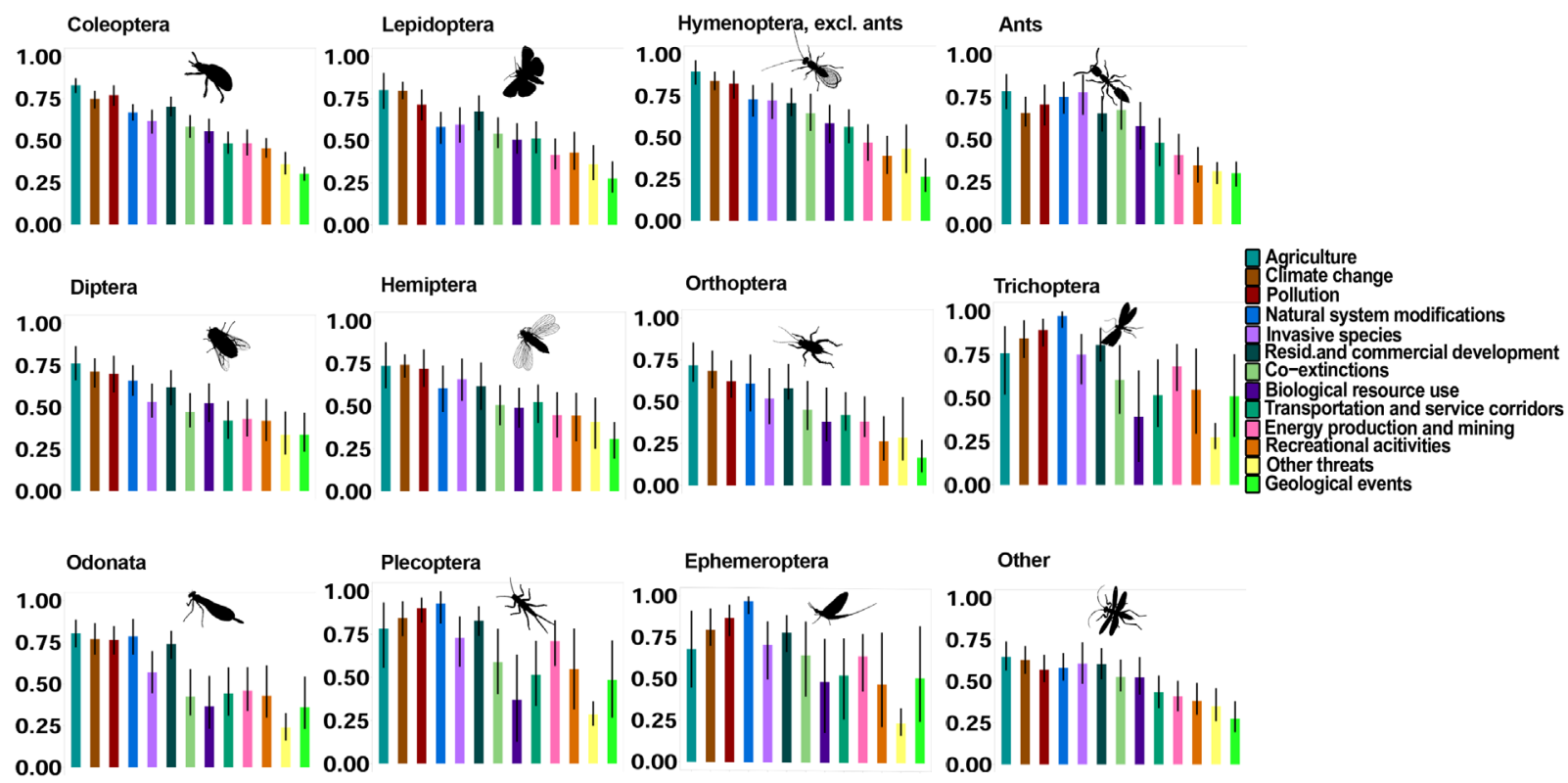

F I G U R E 4 Significance of threats for insects by order. Confidence limits were calculated by bootstrap. Bars represent average relevance scores for each threat based on answers from respondents

diversities, for which the trends were mostly reported as stable or unknown (Figure 5). It is also worth mentioning that, except in the cases of species richness and abundance, around one third of the respondents marked "unknown trend" for the different measures. Regarding the stable and positive trends, species richness was depicted as being mostly stable in Oceania, Indomalaya, and the Afrotropics and beta diversity in space and time in the latter two. On the other hand, biomass was thought to be most stable in the Indomalayan and Nearctic regions, while phylogenetic and functional diversity were marked as having the steadiest trends in the Indomalaya, with $65 \%$ of the answers focused on this area following this opinion, possibly reflecting the fact that unique functions or branches in the tree of life are not necessarily lost at the same pace as other metrics, but not that they are not lost at all. The highest number of answers for positive trends was for the complexity of ecological networks. Proportionally highest values were found for the Australasian and Afrotropical regions, with 27\% and 22\% of respondents indicating an increasing trend for this parameter, respectively. Similarly, the Australasian region had the highest percentage of answers indicating positive trends in phylogenetic diversity, while the Afrotropics and 


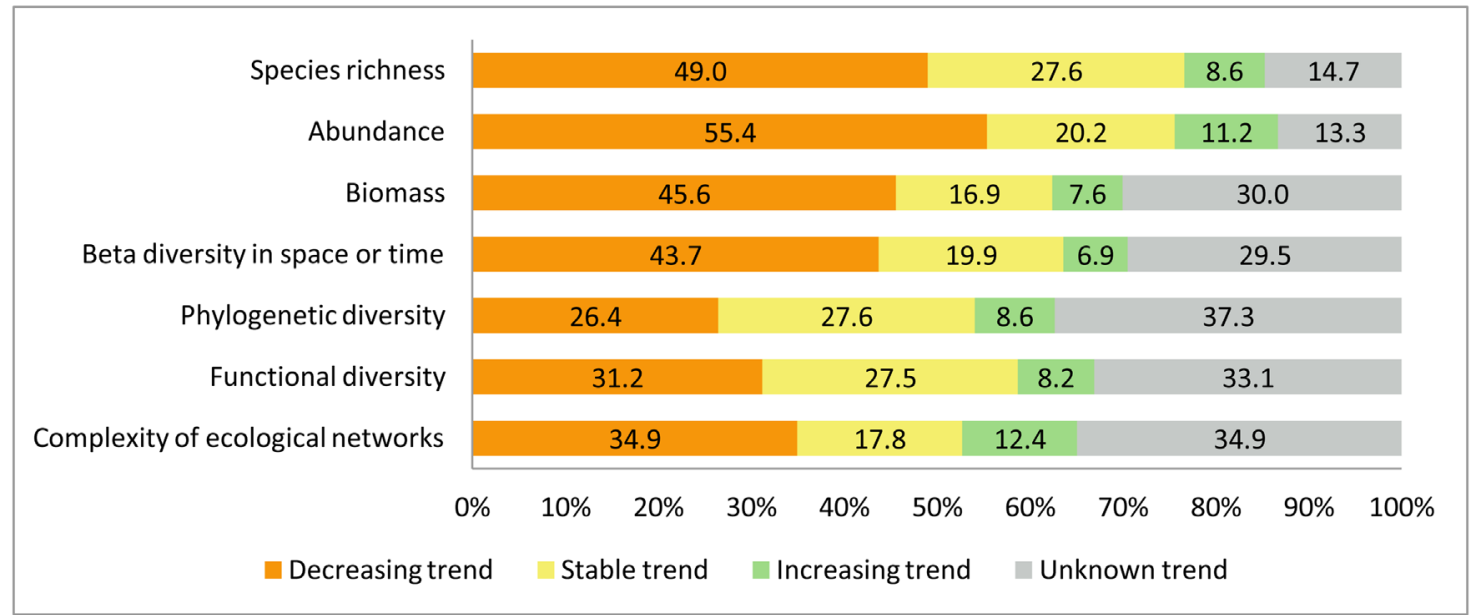

F I G U R E 5 Trends of insect populations. Values (number of answers) are represented in percentages

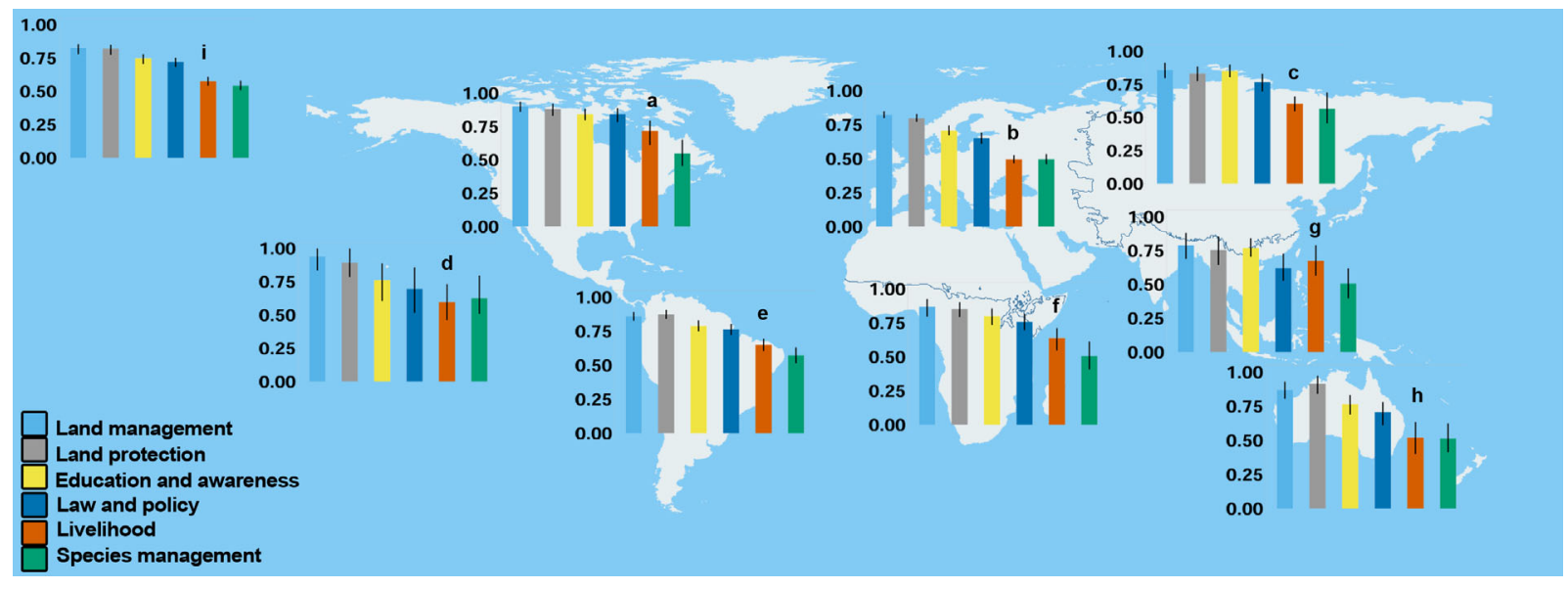

F I G U R E 6 Global and biogeographic section-based significance of conservation measures for the preservation of insects. Confidence limits were calculated by bootstrap. Bars represent average relevance scores for each conservation measure based on answers from respondents. Biogeographic regions: a, Nearctic; b, Western Palaearctic; c, Eastern Palaearctic; d, Oceania; e, Neotropics; f, Afrotropics; g, Indo-Malaya, h, Australasia; i, global

the Nearctic showed most positive trends in functional diversity.

\section{5 | Conservation measures}

The conservation measures considered most (and equally, as revealed by the bootstrap) relevant for the global preservation of insects were land management and land protection (Figure 6). In most cases, answers per biogeographic region followed the global trend, with slight but nonsignificant variations between land management and protection identified as the most important. However, focusing on the differences between geographical regions, in the case of the Nearctic, Indomalayan, and Eastern Palearctic regions, education was listed among the most rele- vant. In the Nearctic region, law and policy was also recognized among the most relevant conservation measures (Figure 6).

There were some differences in answers regarding the most relevant conservation measures between different insect groups (Figure 7). In Hymenoptera, Hemiptera, and Diptera, education was identified among the most relevant conservation measures, next to land protection and land management. In Diptera and Hemiptera, law and policy were also marked as being highly important.

Regarding the allocation of the conservation investments, respondents would primarily dedicate funds for research of insect biodiversity, followed by monitoring of biodiversity and acquisition of new protected areas. Management of protected areas, education and management of unprotected areas would follow, while the smallest amount 


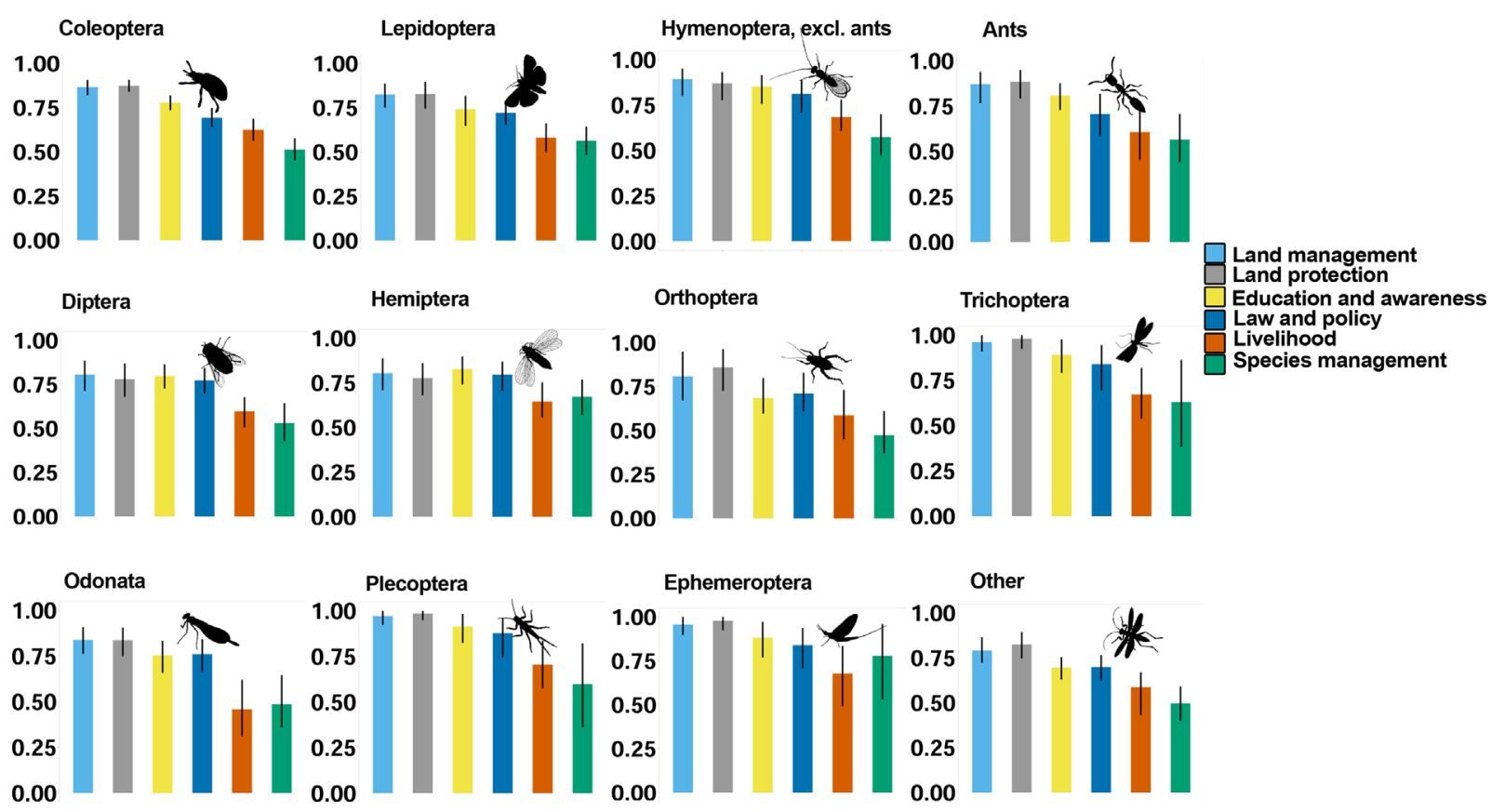

F I G U R E 7 Significance of conservation measures for the preservation of insects by order. Confidence limits were calculated by bootstrap. Bars represent average relevance scores for each conservation measure based on answers from respondents

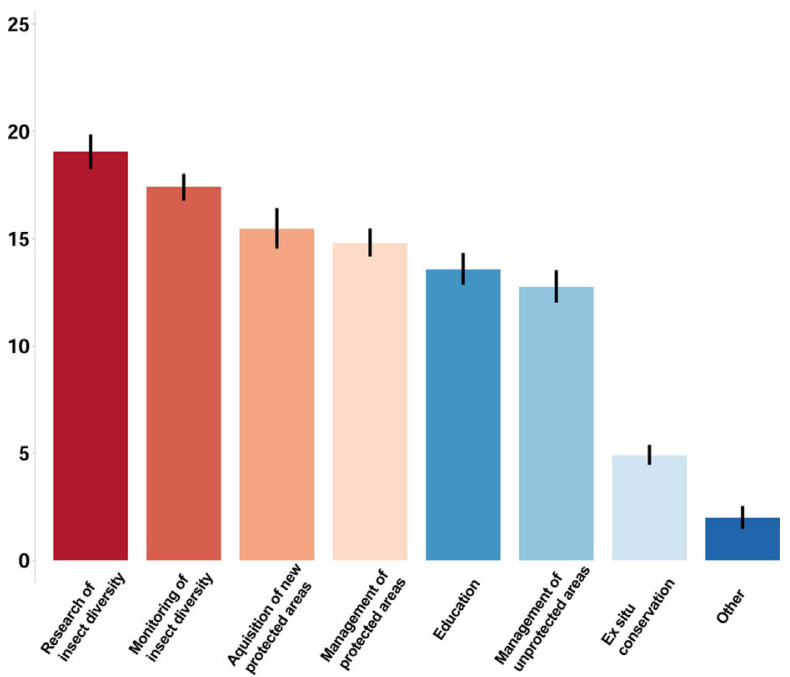

F I G U R E 8 Allocation of funds for conservation investments. Values are calculated as the mean percentage of all given answers for each investment separately

of funds would be allocated to ex-situ conservation of insects (Figure 8).

\section{6 | Services and disservices}

Respondents of the query considered that the most relevant services provided by insects are within provisioning services, namely monitoring of habitat quality and biocontrol (Figure 9). Among regulating services, pollination was depicted as the most significant, while nutrient cycling through saprophagy and coprophagy were the most relevant supporting services. Serving as models for scientific research was the most significant cultural service provided by insects. Pest damage to agriculture and acting as invasive species were selected as main disservices of insects (Figure 10).

\section{4 | DISCUSSION}

Undoubtedly, an understanding of the pros and cons of using expert opinion is valuable when gathering and interpreting data. Although we are aware of the fact that expert opinion is prone to subjectivity, it has already proven to be highly beneficial for conservation science (Martin et al., 2012). For global insect conservation it offers the best available scientific knowledge and fresh perspectives on regions and taxa that have largely remained unexplored. With a wide geographical and taxonomic representation, our study should paint a picture that if not more precise (less variance), then arguably more accurate (less bias), while by using a weighted approach for both regions and taxa we further decrease potential biases.

\section{1 | Threats}

Although recent research on the topic addresses the most common threats for insects, they mainly provide a list of 


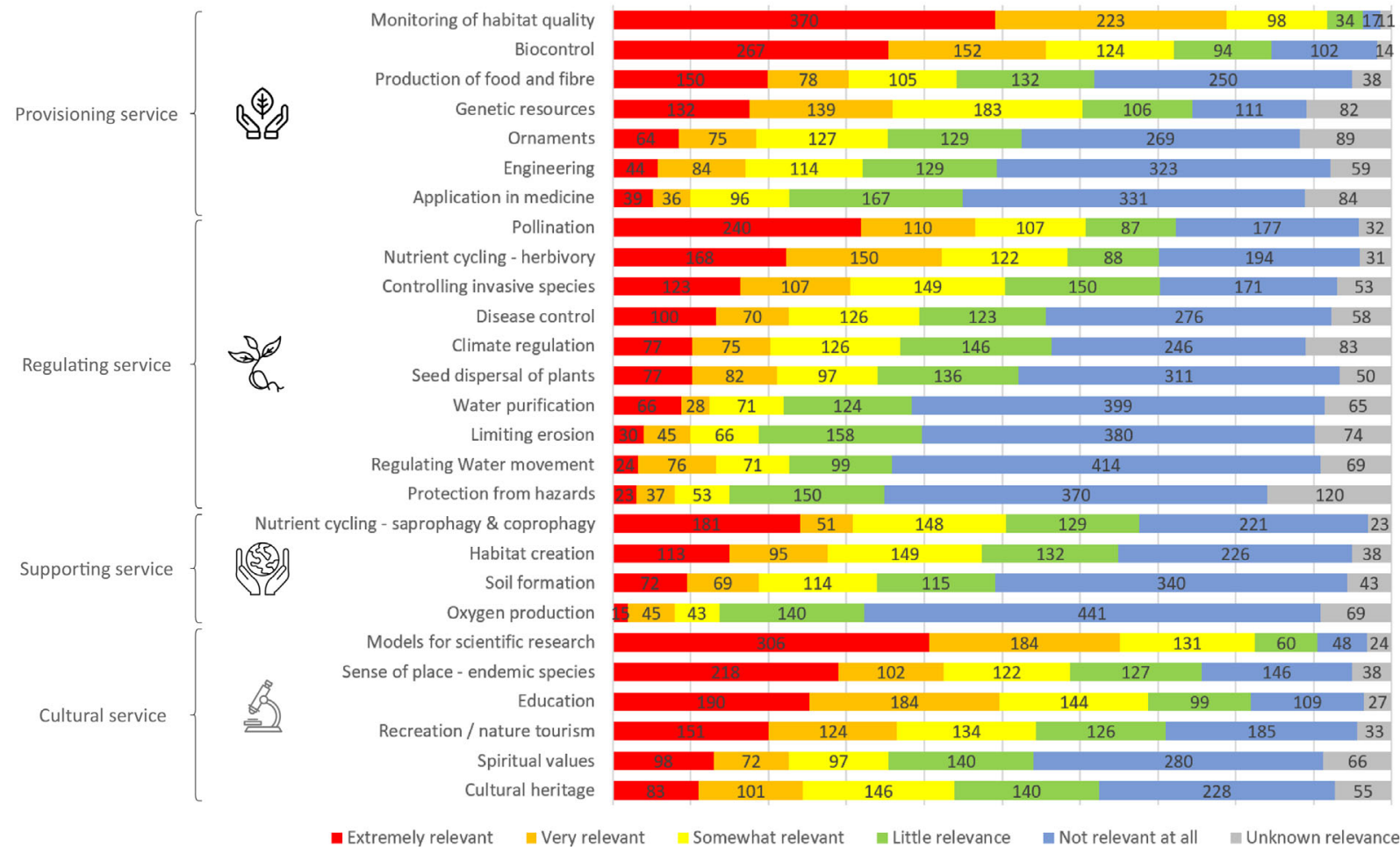

F I G U R E 9 Relevance of insects to the provision of various ecosystem services, as selected by the respondents. Values inside the bars represent the number of answers for the particular option

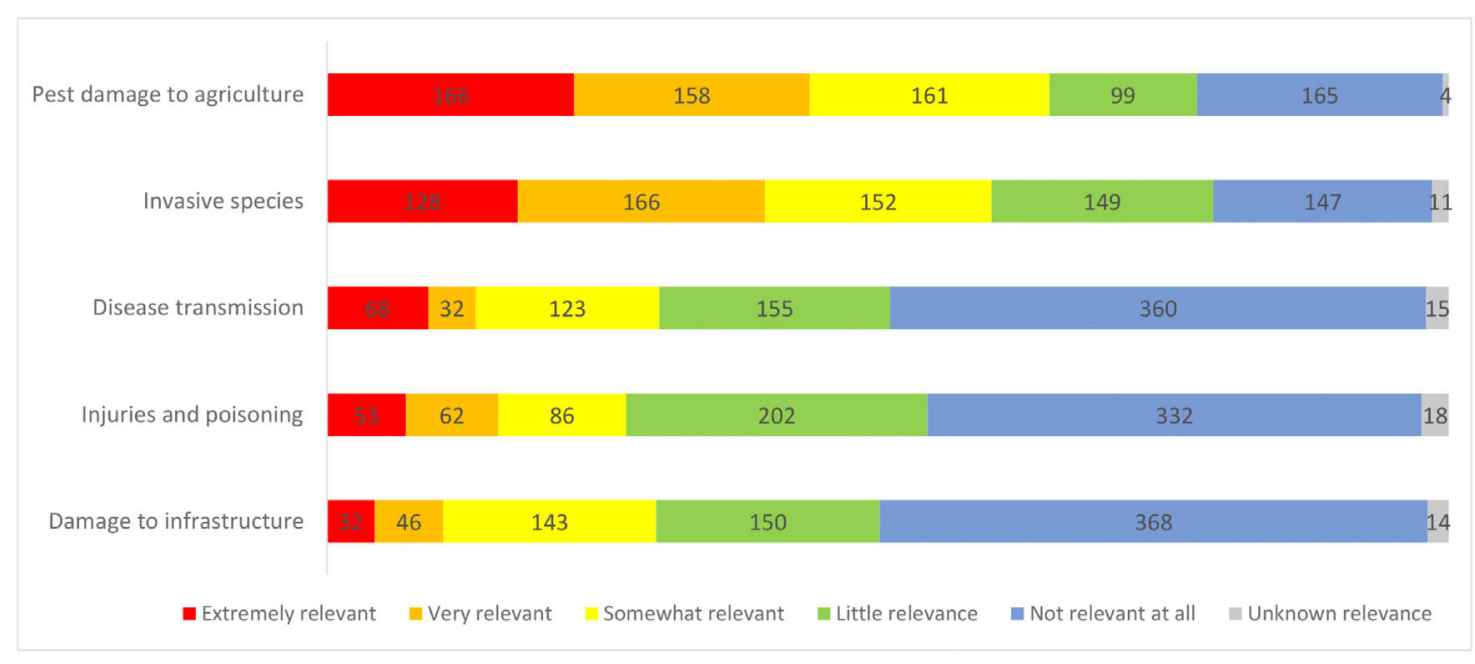

F I G U R E 10 Relevance of insects to the provision of various ecosystem disservices, as selected by the respondents. Values inside the bars represent the number of answers for the particular option

possible threats, without scoring their severity. The Convention on Biological Diversity, representing one of the most significant international legal instruments for biodiversity conservation, recognizes five major pressures (loss, degradation, and fragmentation of natural habitats, overexploitation of biological resources, pollution, impacts of invasive alien species and climate change, and acidifica- tion of the oceans) (Secretariat of the Convention on Biological Diversity, 2014), but does not provide their ranking of importance. To the best of our knowledge, there is only one study scoring the threats for terrestrial, marine and freshwater animal organisms, separately for vertebrates and invertebrates (but not exclusively for insects). (Donaldson et al., 2016). Namely, this study included all animal 
species categorized as threatened on the IUCN Red List, based on the available data in 2012, encompassing 10615 species in total, out of which 3642 were invertebrates (1553 among terrestrial, 1809 in freshwater, and 280 marine). The main threat for terrestrial invertebrates was agriculture, as in our study. Land transformation caused by agricultural activities leads to habitat loss and biotic homogenization (Olden \& Rooney, 2006), both of which subsequently drive the loss of species (Dalzochio et al., 2018; Polus et al., 2007).The second most significant threat in the study of Donaldson et al. (2016) for terrestrial invertebrates was hunting and trapping, which was not scored as extremely relevant in our study. This is probably due to biases in the IUCN red list, whose efforts often focused on taxa known to be hunted for food or pets in many countries, including mollusks and spiders, often hunted and included in illegal pet trade (Fukushima et al., 2019). Despite its importance (Fukushima et al., 2020), and as recognized by the respondents, other threats should be more important for the overall diversity of insects, most of which are not hunted, given their little importance for human consumption. The second most significant threat in our study was climate change. This goes in hand with the existing concern that current climate change impacts on biodiversity are several magnitudes lower than those foreseen for the future and also the fact that it is a recent concern, probably not considered by many of the assessors in IUCN in the past.

Considering the variety of contaminants in the environment that can threaten insects, it is not surprising that pollution was rated as one of the most serious threats among the respondents in our study. Specifically, it was depicted as the second most relevant threat for both Coleoptera and the EPT community. Due to their dependence on water, at least during part of their life cycle, different water effluents constitute a severe threat for these communities (Chi et al., 2017). In a comparable study of Donaldson et al. (2016), pollution was listed as number one stressor for freshwater invertebrates, but not significant for the terrestrial ones.

Certain regions showed a contrasting pattern regarding the scoring of the most severe threats, confirming the presence of geographical variation. In Oceania, agriculture was scored as being a less significant threat than climate change. This might be due to sea-level rise, and increased incidence and intensity of floods and droughts, as a consequence of climate change (Campbell \& Bedford, 2014). Additionally, coextinctions were also depicted as a very important threat for Oceania. The insular nature of this region supports high levels of localized endemism (Kier et al., 2009), with the extinction of host animals or plants for some insect groups promoting the extinction of dependent insects as well. Oceania was also the region where invasive species were given higher weight. Islands are particularly prone to the effects of invasions due to their spatial and temporal isolation (Borges et al., 2020), with native species often incapable of adapting to new competitors, predators, or parasite species. However, it is worth noting that Oceania was the region with the lowest number of respondents. Confidence intervals in this case were proportionally high, so this result should be taken with caution.

In the Indomalayan region, residential and commercial development was marked as a very significant threat, not significantly lower than agriculture and climate change. Wattanachaiyingcharoen et al. (2016) found that a low standard of management in the tourist industry in Thailand may cause an accelerated reduction of the firefly fauna in this region. Furthermore, due to recent unplanned developmental activities, some areas in the Indomalayan region have displayed signs of rapid habitat destruction, negatively affecting biodiversity (Bhattacharya, 2019), which might explain why respondents from this region gave increased weight to this threat.

\section{2 | Population trends}

Due to the extent and severity of threats that insects are facing worldwide (Cardoso et al., 2020; Wagner, 2020), it was somehow expected that respondents would identify a mainly decreasing trend in parameters reflecting the status of insect populations. Depending on the drivers of change, however, there might be some winners as well. Focusing on the portion of answers indicating the existence of a stable, or even an increasing trend, it can be noted that certain biogeographic regions, according to experts, might be less affected by insect population declines. A dominant contribution of a particular insect order to all these positive trends was not observed. This might be interpreted, albeit cautiously, as good news, indicating that there are taxa from different orders managing to cope with the existing pressures causing insect declines.

It is hard to find one reason that would explain stable or positive trends in different biogeographical regions, each of them possibly requiring different reasoning. We hypothesize that the Afrotropics, Indomalayan, and Australasian regions (i.e., certain areas in those regions), which showed most stable and positive trends for different population metrics, are less affected by habitat loss than the others, providing relatively large areas of natural habitats, thus managing to sustain large and stable populations of different insect groups. Globally, the levels of deforestation in the period 2015-2020 had a decreasing trend compared to 2010-2015 (FAO \& UNEP, 2020). However, in spite of a generally decreasing trend, these levels are still high, with the largest losses attributed to Brazil (Weisse \& Goldman, 2020). Another reason might be that 
in general there are less studies reflecting and quantifying habitat loss in these areas, compared to the well investigated Western Paleartic or the Neotropics (Ramsfield et al., 2016).

Nevertheless, it is noteworthy that in almost one third of the answers respondents selected unknown trends, which indicates that, even with the recent rise in the number of papers tackling insect declines, the most diverse class of animal organisms on the planet is still severely understudied, hence a nuanced view of insect declines or increases according to taxon and region is needed (Montgomery et al., 2020).

\section{3 $\mid$ Conservation measures}

In our study, land management and land protection were recognized as the most relevant conservation measures for the global preservation of insects across regions and taxa. Many regions worldwide have been lagging in the protection of relevant areas for insect conservation (Taylor et al., 2018). Taking a landscape perspective to protection and management of insect biotopes is in fact one of the most effective ways to protect countless taxa, their unique ways of life, evolutionary history, and complex networks (Samways et al., 2020). Increasing the area and connectivity of protected zones promotes richer insect communities, particularly regarding sensitive orders with specific habitat requirements, such as the EPT (South et al., 2019).

Next to land management and land protection, the respondents highlighted education as a highly relevant conservation measure. Education is listed as the second most important conservation measure for the Indomalayan and Eastern Palearctic regions, before land protection (albeit not significantly). Information about the Indomalayan fauna is politically and linguistically fragmented among numerous publications. Often it is not easy to obtain information from conservation literature, as it is more focused on vertebrate species while insects are clearly under-represented (Di Marco et al., 2017). Insufficient research attention in these regions when it comes to insects leaves a mark on environmental education activities. Education and education campaigns as a tool for conservation were particularly recognized by those who responded to the survey for the orders Hemiptera and Diptera. Dealing with large gaps in taxonomical, biological, and ecological knowledge of insects should be of high priority on all educational levels. A recent, comprehensive review revealed that education, prompts and feedback interventions resulted in positive environmental behavior when it comes to conservation volunteering (Thomas-Walters et al., 2020). However, the authors argued that the strongest impact could be achieved only by combined multiple interventions, which has been also suggested by a recent study dealing with education and behavioral transformations in the field of conservation policies (Marselle et al., 2020). Citizen science projects combined with education programs could create a natural learning environment and greatly increase community-based conservation outcomes, providing data with clear conservation relevance (Oberhauser \& Prysby, 2008), as well as favoring connection between citizens and scientists.

According to the respondents, the least relevant among all conservation measures was species management. A recent survey of biodiversity experts (Javeline et al., 2015) identified managed relocation as one of the most effective strategies in reducing extinction risks for insects due to climate change. However, this strategy can lead to unintended harmful consequences, such as putting nontarget species at risk. A common challenge in insect species conservation and management is how to manage species of which our knowledge is limited, particularly in relation to life-cycle interventions, which is a pre-requisite for the successful implementation of management actions. Moreover, handling the enormous richness of insect orders makes it difficult to manage species individually. Nevertheless, species management may be a tool to be explored further in insect conservation, namely for relatively well-known species within very limited areas that undergo habitat recovery. For instance, big progress in the Lord Howe Island stick insect's conservation story assures that careful species management could lead to successful reintroduction of a critically endangered insect species within the next few years (McGrath et al., 2017).

The respondents indicated that they would primarily fund research and monitoring of insect biodiversity. It was interesting to read one of the comments a respondent wrote, "I enjoyed the allocation exercise. As with most of the tropics, the Asian tropics host a high level of insect biodiversity, but a relatively poor understanding of what is out there and what to do with it. For this reason, my suggested allocations were more heavily weighted to research and monitoring then I might otherwise prefer (which is to generally prioritize protected area establishment and management)." Incorporating insects into protected area monitoring activities is possible only with well-documented species inventories (McGeoch et al., 2011), which brings us back to the recognized gaps in taxonomical, biological, and ecological knowledge of insects and the need to build unbiased monitoring programs at a global scale (Cardoso \& Leather, 2019). We do assume that experts involved in insect-related research studies would place research and monitoring at the top of the conservation measure investments scale, confirming the subjective view that expert opinion sometimes brings. This was further verified by the 
respondents engaged in management or decision making, who prioritized management of both protected and unprotected areas (and education) over research and monitoring.

\section{4 $\quad$ Services and disservices}

A recent study shows that the most studied ecosystem services provided by insects are pollination, biological control, food provisioning and recycling organic matter (Noriega et al., 2018). Beside biocontrol, the respondents selected monitoring of habitat quality as the most relevant service among provisioning services. Among the regulating and supporting services, as expected, pollination and nutrient cycling through saprophagy and coprophagy were selected as the most significant. Most likely due to the subjective nature of expert opinion, the experts in our study recognized serving as models for scientific research as the most significant cultural service provided by insects. Indeed, this ecosystem service provided by insects has been discussed in many recent studies in different scientific fields worldwide, including evolutionary (Wang et al., 2016), toxicology (Coates et al., 2019), biomonitoring (Miguel et al., 2017), and robotics research (Mintchev et al., 2017). Although acknowledgment of cultural and spiritual values of insects in relation to their conservation has been recently introduced in studies (Hill et al., 2019; Greyvenstein et al., 2020), the respondents somehow neglected these services.

Pest damage to agriculture and species invasions were listed as the most significant disservices. The flows of services and disservices, at least in agricultural ecosystems, directly depend on how ecosystems are managed at different landscape scales (Zhang et al., 2007) and this should be considered when planning policy-relevant entomological research that can influence agricultural practices. Conversely, most experts listed disservices such as disease transmission and injuries and poisoning as not relevant at all, probably due to prior knowledge (which has an effect on general attitudes toward poisonous and venomous animals). A recent study (Tomažič et al. 2020) shows that even a short exposure to live animals, perceived or actually dangerous, can have a positive influence to human attitudes. The authors argue that the presentation of the common poisonous insects in the media is unequal; positive for bees, but less favorable for wasps and least for mosquitos. A constructive expert role in public dialogues could contribute to specific knowledge (Reincke et al., 2020) and mitigate fears to appropriate proportions. In any case, this is somewhat surprising, given the role of insects, namely Diptera, in spreading numerous deadly diseases, but might reveal some bias against tropical settings in the expertise.

\subsection{Implications for conservation and management}

Our study suggests that using inputs from experts can provide useful insights on the planning and implementation of insect conservation management and policy. For instance, although agriculture and climate change are profoundly affecting biodiversity worldwide, there are certain areas, mostly in tropical regions, where residential and commercial development was among the top-rated threats. In this scenario, when threats recognized can be significantly influenced locally or regionally (through the integration of biodiversity into local policies and developmental schemes), priority actions should be tailored to suit these specific regions. One such conservation effort based on extensive research on hoverfly species and their habitats in Serbia enjoyed a high level of success generating an important legal achievement; three areas were protected based exclusively on hoverfly fauna (Pil \& Vujić, 2004). This is the first example of site protection hinged solely on diversity and the importance of Dipteran species in Europe (Vujić et al., 2016) and could serve as a model for future use. Furthermore, insights from experts regarding the allocation of funding might be a valuable asset when shaping conservation policies, taking into account important relations between threats, conservation actions, and their impact on biodiversity, as well as limited funds. Determining such relationships is crucial for selecting conservation actions that will lead to desired outcomes (Carwardine et al., 2012).

\section{5 | CONCLUSION}

Our study shows that experts consider agriculture, climate change, and pollution as the three main drivers for insect declines, while land protection and land management are identified as the most prominent conservation measures that might aid in the preservation of insects and mitigation of negative consequences worldwide. However, there was variation in both the threats and conservation measures identified as the most relevant across different biogeographic regions and taxonomic groups. This suggests that each case must be studied individually when addressing threats and designing conservation actions, depending on the target area or taxonomic group of species. A decreasing trend in parameters reflecting the status of insect populations, as well as the extreme significance of insects, as reflected in the numerous ecosystem services they provide, calls for global monitoring programs and a specialized approach in conservation for each particular case. Expert opinion could 
be our best bet in many regions where data are scarce, shedding new light on understudied regions and insect taxa.

\section{ACKNOWLEDGMENTS}

We would like to thank all the experts for generously sharing their time and expertise, Marina Sulc for the help and advice regarding data analysis and visualization, and Jagoba Malumbres-Olarte for the illustration following this paper. We give attribution to George Starr (Ephemeroptera, link to license https://creativecommons. org/licenses/by-nc-sa/3.0/), Maxime Dahirel (Odonata, https://creativecommons.org/licenses/by/3.0/), Melissa Broussard (Orthoptera, https://creativecommons. org/licenses/by/3.0/), Nico Muñoz (Pleoptera, https: //creativecommons.org/licenses/by-nc/3.0/), and Didier Descouens (vectorized by T. Michael Keesey) (Trichoptera, https://creativecommons.org/licenses/by-sa/3.0/) for material downloaded from website Phylopic. M.M. and S.P. acknowledge financial support of the Ministry of Education, Science and Technological Development of the Republic of Serbia (Grant Nos. 451-03-9/202114/200358 and 451-03-9/2021-14/200125) and H2020 Project ANTARES, grant no. 664387. V.V.B. and P.C. are supported by Kone Foundation.

\section{AUTHOR CONTRIBUTIONS}

P.C. and M.M. participated in the design of the study. M.M. and S.P. wrote the paper, participated in data collection, and prepared graphics. M.M. and V.B. performed the analyses. All authors contributed to the writing and gave final approval.

\section{ETHICS STATEMENT}

Ethical compliance statement was provided by independent ethics advisor, Prof. Dr. Gordana Vilotijević Dautović, professor of Medical ethics at Faculty of Medicine, University of Novi Sad.

\section{DATA ACCESSIBILITY STATEMENT}

The data that support the findings of this study are available on request from the corresponding author. The data are not publicly available due to privacy or ethical restrictions.

\section{CONFILCT OF INTEREST}

The authors declare no conflict of interest.

\section{O R C I D}

Marija Miličić (D) https://orcid.org/0000-0002-3154-660X

Snežana Popov (10 https://orcid.org/0000-0001-9892-8998

Vasco Veiga Branco (1D https://orcid.org/0000-0001-7797-

3183

Pedro Cardoso (1) https://orcid.org/0000-0001-8119-9960

\section{REFERENCES}

Bhattacharya, S. (2019). Environmental crisis in the eastern Himalayan landscapes in India. Consilience, 21(1), 66-85. https://doi.org/10.7916/consilience.v0i21.5729

Biesmeijer, J. C., Roberts, S. P. M., Reemer, M., Ohlemueller, R., Edwards, M., Peeters, T., ... Kunin, W. E. (2006). Parallel declines in pollinators and insect-pollinated plants in Britain and The Netherlands. Science, 313(5785), 351-354. https://doi.org/10.1126/ science. 1127863

Borges, P. A. V., Rigal, F., Ros-Prieto, A., \& Cardoso, P. (2020). Increase of insular exotic arthropod diversity is a fundamental aspect of the current biodiversity crisis. Insect Conservation and Diversity, 13(5), 508-518. https://doi.org/10.1111/icad.12431

Brooks, D. R., Bater, J. E., Clark, S. J., Monteith, D. T., Andrews, C., Corbett, S. J., Beaumont, D. A., \& Chapman, J. W. (2012). Large carabid beetle declines in a United Kingdom monitoring network increases evidence for a widespread loss in insect biodiversity. Journal of Applied Ecology, 49, 1009-1019. https://doi.org/10.2307/ 23353466

Campbell, J., \& Bedford, R. (2014). Migration and climate change in the Pacific. In: (E. Piguet \& F. Laczko Eds.), People on the move in a changing climate (pp. 177-204). Dordrecht: Springer.

Cardoso, P., \& Leather, S. (2019). Predicting a global insect apocalypse. Insect Conservation and Diversity, 12(4), 263-267. https://doi. org $/ 10.1111 /$ icad.12367

Cardoso, P., Barton, P. S., Birkhofer, K., Chichorro, F., Deacon, C., Fartmann, T., ... Samways, M. J. (2020). Scientists' warning to humanity on insect extinctions. Biological Conservation, 242, 108426. https://doi.org/10.1016/j.biocon.2020.108426

Cardoso, P., Branco, V., Chichorro, F., Fukushima, C., \& MacíasHernández, N. (2019). Can we really predict a catastrophic worldwide decline of entomofauna and its drivers? Global Ecology and Conservation, 20, e00621. https://doi.org/10.1016/j.gecco.2019. e00621

Carwardine, J., O'Connor, T., Legge, S., Mackey, B., Possingham, H. P., \& Martin, T. G. (2012). Prioritizing threat management for biodiversity conservation. Conservation Letters, 5(3), 196-204. https: //doi.org/10.1111/j.1755-263X.2012.00228.x

Chi, S., Hu, J., Zheng, J., \& Dong, F. (2017). Study on the effects of arsenic pollution on the communities of macro-invertebrate in Xieshui River. Acta Ecologica Sinica, 37(1), 1-9. https://doi.org/10. 1016/j.chnaes.2016.09.003

Coates, C. J., Lim, J., Harman, K., Rowley, A. F., Griffiths, D. J., Emery, H., \& Layton, W. (2019). The insect, Galleria mellonella, is a compatible model for evaluating the toxicology of okadaic acid. Cell Biology and Toxicology, 35(3), 219-232. https://doi.org/10.1007/ s10565-018-09448-2

Cook, C. N., Hockings, M., \& Carter, R. W. (2010). Conservation in the dark? The information used to support management decisions. Frontiers in Ecology and the Environment, 8(4), 181-186. https:// doi.org/10.1890/090020 
Dalzochio, M. S., Périco, E., Renner, S., \& Sahlén, G. (2018). Effect of tree plantations on the functional composition of Odonata species in the highlands of southern Brazil. Hydrobiologia, 808(1), 283300. https://doi.org/10.1007/s10750-017-3431-9

Desquilbet, M., Gaume, L., Grippa, M., Céréghino, R., Humbert, J. F., Bonmatin, J. M., ... Goulson, D. (2020). Comment on "Metaanalysis reveals declines in terrestrial but increases in freshwater insect abundances.. Science, 370(6523),. https://doi.org/10.1126/ science.abd8947

Di Marco, M., Chapman, S., Althor, G., Kearney, S., Besancon, C., Butt, N., ... Watson, J. E. M. (2017). Changing trends and persisting biases in three decades of conservation science. Global Ecology and Conservation, 10, 32-42. https://doi.org/10.1016/j.gecco.2017. 01.008

Didham, R. K., Basset, Y., Collins, C. M., Leather, S. R., Littlewood, N. A., Menz, M. H., ... Stewart, A. J. (2020). Interpreting insect declines: seven challenges and a way forward. Insect Conservation and Diversity, 13(2), 103-114. https://doi.org/10.1111/icad.12408

Donaldson, M., Burnett, N., Braun, D., Suski, C., Hinch, S., Cooke, S., \& Kerr, J. (2016). Taxonomic bias and international biodiversity conservation research. Facets, 1(1), 105-113. https://doi.org/10. 1139/facets-2016-0011

FAO and UNEP. (2020). The State of the World's Forests 2020. Forests, biodiversity and people. Rome.

Fukushima, C. S., Mammola, S., \& Cardoso, P. (2020). Global wildlife trade permeates the Tree of Life. Biological Conservation, 247, 108503. https://doi.org/10.1016/j.biocon.2020.108503

Fukushima, C., Mendoza, J. I., West, R. C., Longhorn, S. J., Rivera, E., Cooper, E. W., ... Cardoso, P. (2019). Species conservation profiles of tarantula spiders (Araneae, Theraphosidae) listed on CITES. Biodiversity Data Journal, 7.

Goulson, D., Nicholls, E., Botías, C., \& Rotheray, E. (2015). Bee declines driven by combined stress from parasites, pesticides, and lack of flowers. Science, 347, 6229. https://doi.org/10.1126/science. 1255957

Greyvenstein, B., Du Plessis, H., \& Van den Berg, J. (2020). The charismatic praying mantid: a gateway for insect conservation. African Zoology, 55(1), 109-118. https://doi.org/10.1080/15627020. 2020.1732834

Hallmann, C. A., Sorg, M., Jongejans, E., Siepel, H., Hofland, N., Schwan, H., ... de Kroon, H. (2017). More than 75\% decline over 27 years in total flying insect biomass in protected areas. PLoS One, 12(10), e185809. https://doi.org/10.1371/journal.pone.0185809

Hill, R., Nates-Parra, G., Quezada-Euán, J. J. G., Buchori, D., LeBuhn, G., Maués, M. M., ... da Cunha, M. C. (2019). Biocultural approaches to pollinator conservation. Nature Sustainability, 2(3), 214-222. https://doi.org/10.1038/s41893-019-0244-Z

Javeline, D., Hellmann, J. J., McLachlan, J. S., Sax, D. F., Schwartz, M. W., Castro Cornejo, R., ... Reid, R. (2015). Expert opinion on extinction risk and climate change adaptation for biodiversityExpert opinion on climate change adaptation. Elementa: Science of the Anthropocene, 3. https://doi.org/10.12952/journal.elementa. 000057

Kier, G., Kreft, H., Lee, T. M., Jetz, W., Ibisch, P. L., Nowicki, C., ... Barthlott, W. (2009). A global assessment of endemism and species richness across island and mainland regions. Proceedings of the National Academy of Sciences of the United States of America, 106(23), 9322-9327. https://doi.org/10.1073/pnas.0810306106
Krause, M., \& Robinson, K. (2017). Charismatic species and beyond: how cultural schemas and organisational routines shape conservation. Conservation and Society, 15(3), 313-321. https://doi.org/10. 4103/cs.cs_16_63

Mammola, S., Riccardi, N., Prié, V., Correia, R., Cardoso, P., LopesLima, M., \& Sousa, R. (2020). Towards a taxonomically unbiased European Union biodiversity strategy for 2030. Proceedings of the Royal Society B, 287, 20202166. https://doi.org/10.1098/rspb.2020. 2166

Marselle, M. R., Turbe, A., Shwartz, A., Bonn, A., \& Colléony, A. (2020). Addressing behavior in pollinator conservation policies to combat the implementation gap. Conservation Biology, https: //doi.org/10.1111/cobi.13581

Martin, T. G., Burgman, M. A., Fidler, F., Kuhnert, P. M. Low-Choy, S., McBride, M., \& Mengersen, K. (2012). Eliciting expert knowledge in conservation science. Conservation Biology, 26(1), 29-38. https://doi.org/10.1111/j.1523-1739.2011.01806.x

McGeoch, M. A., Sithole, H., Samways, M. J., Simaika, J. P., Pryke, J. S., Picker, M., ... Hamer, M. (2011). Conservation and monitoring of invertebrates in terrestrial protected areas. Koedoe, 53(2), 131143. https://doi.org/10.4102/koedoe.v54i1.1000

McGrath, S. J., Cleave, R. J., Elgar, M. A., Silcocks, S. C., \& Magrath, M. J. (2017). Determining host plant preferences for the critically endangered Lord Howe Island stick insect (Dryococelus australis) to assist reintroduction. Journal of Insect Conservation, 21(5-6), 791-799. https://doi.org/10.1007/s10841-017-0002-3

Miguel, T. B., Oliveira-Junior, J. M. B., Ligeiro, R., \& Juen, L. (2017). Odonata (Insecta) as a tool for the biomonitoring of environmental quality. Ecological Indicators, 81, 555-566. https://doi.org/10.1016/ j.ecolind.2017.06.010

Mintchev, S., de Rivaz, S., \& Floreano, D. (2017). Insectinspired mechanical resilience for multicopters. IEEE Robotics and Automation Letters, 2(3), 1248-1255. https: //doi.org/10.1109/LRA.2017.2658946

Montgomery, G. A., Dunn, R. R., Fox, R., Jongejans, E., Leather, S. R., Saunders, M. E., ... Wagner, D. L. (2020). Is the insect apocalypse upon us? How to find out. Biological Conservation, 241, 108327. https://doi.org/10.1016/j.biocon.2019.108327

Noriega, J. A., Hortal, J., Azcárate, F. M., Berg, M. P., Bonada, N., Briones, M. J. I., ... Santos, A. M. C. (2018). Research trends in ecosystem services provided by insects. Basic and Applied Ecology, 26, 8-23. https://doi.org/10.1016/j.baae.2017.09.006

Oberhauser, K., \& Prysby, M. D. (2008). Citizen science: creating a research army for conservation. American Entomologist, 54(2), 103-105. https://doi.org/10.1093/ae/54.2.103

Oksanen, J., Blanchet, F. G., Friendly, M., Kindt, R., Legendre, P., McGlinn, D., ... Wagner, H. (2019). vegan: Community Ecology Package. R package version 2.5-4. https://CRAN.R-project.org/ package $=$ vegan

Olden, J. D., \& Rooney, T. P. (2006). On defining and quantifying biotic homogenization. Global Ecology and Biogeography, 15(2), 113-120. https://doi.org/10.1111/j.1466-822X.2006.00214.X

Patterson, J., Meek, M. E., Strawson, J. E., \& Liteplo, R. G. (2007). Engaging expert peers in the development of risk assessments. Risk Analysis, 27(6), 1609-1621. https://doi.org/10.1111/j.1539-6924. 2007.00992.x

Pil, N., \& Vujić, A. (2004). The importance of wetland habitats of Fruška Gora Mt. for existance of rare and endemic hoverflies (D: $s)$. 
Novi Sad: International Association for Danube Research, 35, $13-$ 19.

Polus, E., Vandewoestijne, S., Choutt, J., \& Baguette, M. (2007). Tracking the effects of one century of habitat loss and fragmentation on calcareous grassland butterfly communities. Biodiversity and Conservation, 16(12), 3423-3436. https://doi.org/10.1007/ s10531-006-9008-y

Ramsfield, T. D., Bentz, B. J., Faccoli, M., Jactel, H., \& Brockerhoff, E. G. (2016). Forest health in a changing world: effects of globalization and climate change on forest insect and pathogen impacts. Forestry, 89(3), 245-252. https://doi.org/10.1093/forestry/ cpw018

Reincke, C. M., Bredenoord, A. L., \& van Mil, M. H. (2020). From deficit to dialogue in science communication: the dialogue communication model requires additional roles from scientists. $E M B O$ Reports, 21(9), e51278. 10.15252/embr.202051278

Roth, N., Zoder, S., Zaman, A., Thorn, S., \& Schmidl, J. (2020). Longterm monitoring reveals decreasing water beetle diversity, loss of specialists and community shifts over the past 28 years. Insect Conservation and Diversity, 13(2), 140-150. https://doi.org/10.1111/icad. 12411

Samways, M. J., Barton, P. S., Birkhofer, K., Chichorro, F., Deacon, C., Fartmann, T., ... Hill, M. J. (2020). Solutions for humanity on how to conserve insects. Biological Conservation, 242, 108427. https:// doi.org/10.1016/j.biocon.2020.108427

Secretariat of the Convention on Biological Diversity (2014). Global Biodiversity Outlook 4. Montréal, 155 pages.

Shortall, C. R., Moore, A., Smith, E., Hall, M. J., Woiwod, I. P., \& Harrington, R. (2009). Long-term changes in the abundance of flying insects. Insect Conservation and Diversity, 2(4), 251-260. https: //doi.org/10.1111/j.1752-4598.2009.00062.x

Simmons, B. I., Balmford, A., Bladon, A. J., Christie, A. P., De Palma, A., Dicks, L. V., ... Finch, T. (2019). Worldwide insect declines: an important message, but interpret with caution. Ecology and Evolution, 9, 3678-3680. https://doi.org/10.1002/ece3.5153

South, E. J., DeWalt, R. E., \& Cao, Y. (2019). Relative importance of Conservation Reserve Programs to aquatic insect biodiversity in an agricultural watershed in the Midwest, USA. Hydrobiologia, 829(1), 323-340. https://doi.org/10.1007/s10750-018-3842-2

Stork, N. E. (2018). How many species of insects and other terrestrial arthropods are there on Earth? Annual Review of Entomology, 63, 31-45. https://doi.org/10.1146/annurev-ento-020117-043348

Sutherland, W. J., Pullin, A. S., Dolman, P. M., \& Knight, T. M. (2004). Response to Griffiths. Mismatches between conservation science and practice. Trends in Ecology \& Evolution, 19(11), 565-566. https: //doi.org/10.1016/j.tree.2004.09.005

Taylor, G. S., Braby, M. F., Moir, M. L., Harvey, M. S., Sands, D. P. A., New, T. R., ... Weinstein, P. (2018). Strategic national approach for improving the conservation management of insects and allied invertebrates in Australia. Austral Entomology, 57(2), 124-149. https://doi.org/10.1111/aen.12343

Thomas-Walters, L., McCallum, J., Montgomery, R., Wan, A. K. Y., $\&$ Veríssimo, D. (2020). A systematic review of conservation efforts using non-monetary, non-regulatory incentives to promote voluntary behaviour change. https://doi.org/10.31235/osf.io/6dhaf

Titley, M. A., Snaddon, J. L., \& Turner, E. C. (2017). Scientific research on animal biodiversity is systematically biased towards vertebrates and temperate regions. PloS one, 12(12), e0189577. https://doi.org/ 10.1371/journal.pone.0189577

Tomažič, I., Hummel, E., Schrenk, M., Rupnik, T., \& Randler, C. (2020). Cognitive and affective outcomes of teaching about poisonous and venomous animals. Journal of Biological Education, 54(1), 63-76. https://doi.org/10.1080/00219266.2018.1546757

van Klink, R. Bowler, D. E., Gongalsky, K. B., Swengel, A. B., Gentile, A., \& Chase, J. M. (2020). Meta-analysis reveals declines in terrestrial but increases in freshwater insect abundances. Science, 368(6489), 417-420. https://doi.org/10.1126/science.aax9931

Vujić, A., Radenković, S., Nikolić, T., Radišić, D., Trifunov, S., Andrić, A., ... Lugonja, P. (2016). Prime Hoverfly (Insecta: diptera: syrphidae) areas (PHA) as a conservation tool in Serbia. Biological Conservation, 198, 22-32. https://doi.org/10.1016/j.biocon.2016.03.032

Wagner, D. L. (2020). Insect declines in the Anthropocene. Annual Review of Entomology, 65, 457-480. https://doi.org/10.1146/ annurev-ento-011019-025151

Wang, B., Xia, F., Engel, M. S., Perrichot, V., Shi, G., Zhang, H., ... Rust, J. (2016). Debris-carrying camouflage among diverse lineages of Cretaceous insects. Science Advances, 2(6), https://doi. org/10.1126/sciadv.1501918

Wattanachaiyingcharoen, W., Nak-eiam, S., Phanmuangma, W., Booninkiaew, S., \& Nimlob, N. (2016). Species diversity of firefly (Coleoptera: lampyridae) in the highlands of northern Thailand. NU International Journal of Science, 13(2), 24-32. https://www.sci. nu.ac.th/sciencejournal/index.php/journal/article/view/310

Weisse, M., \& Goldman, E. D. ((2020). June 02). We Lost a Football Pitch of Primary Rainforest Every 6 Seconds in 2019. https://www. wri.org/blog/2020/06/global-tree-cover-loss-data-2019

Zhang, W., Ricketts, T. H., Kremen, C., Carney, K., \& Swinton, S. M. (2007). Ecosystem services and dis-services to agriculture. Ecological Economics, 64(2), 253-260. https://doi.org/10.1016/j.ecolecon. 2007.02.024

\section{SUPPORTING INFORMATION}

Additional supporting information may be found online in the Supporting Information section at the end of the article.

How to cite this article: Miličić M, Popov S, Branco VV, Cardoso P. Insect threats and conservation through the lens of global experts. Conservation Letters. 2021;14:e12814.

https://doi.org/10.1111/conl.12814 